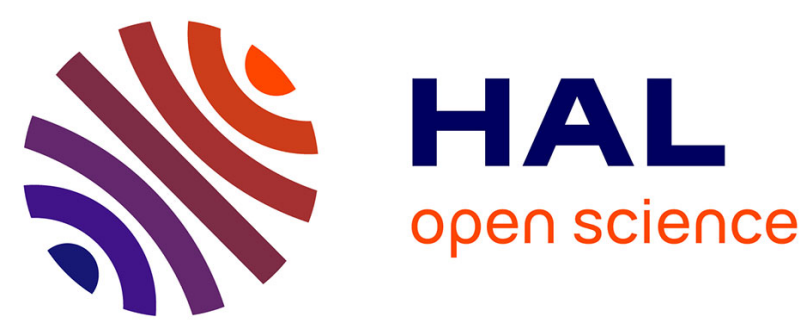

\title{
Collective and individual interdisciplinarity in a sustainability research group: A social network analysis
}

Bruno Locatelli, Améline Vallet, Jacques Tassin, Denis Gautier, Aurélie Chamaret, Plinio Sist

\section{- To cite this version:}

Bruno Locatelli, Améline Vallet, Jacques Tassin, Denis Gautier, Aurélie Chamaret, et al.. Collective and individual interdisciplinarity in a sustainability research group: A social network analysis. Sustainability Science, 2021, 16, pp.37-52. 10.1007/s11625-020-00860-4 cirad-03012979

\section{HAL Id: cirad-03012979 \\ http://hal.cirad.fr/cirad-03012979}

Submitted on 18 Nov 2020

HAL is a multi-disciplinary open access archive for the deposit and dissemination of scientific research documents, whether they are published or not. The documents may come from teaching and research institutions in France or abroad, or from public or private research centers.
L'archive ouverte pluridisciplinaire HAL, est destinée au dépôt et à la diffusion de documents scientifiques de niveau recherche, publiés ou non, émanant des établissements d'enseignement et de recherche français ou étrangers, des laboratoires publics ou privés. 


\title{
Collective and individual interdisciplinarity in a sustainability research group: A social network analysis
}

Bruno Locatelli $(1,2 *)$, Améline Vallet $(3,4)$, Jacques Tassin (1), Denis Gautier (1), Aurélie Chamaret (5), Plinio Sist (1)

1. Cirad, Univ Montpellier, 34398 Montpellier, France

2. Cifor, Lima, Peru

3. Ecologie Systématique Evolution, AgroParisTech, CNRS, Université Paris-Sud, Université Paris-Saclay, Orsay, France

4. CIRED, AgroParisTech, Cirad, CNRS, EHESS, Ecole des Ponts ParisTech, Université

Paris-Saclay, Nogent-sur-Marne, France

5. Pacte, Univ Grenoble-Alpes, Grenoble, France

*: Corresponding author, bruno.locatelli@cirad.fr, Tel: +511 3496017

Accepted manuscript of the following paper: Locatelli B., Vallet A., Tassin J., Gautier D., Chamaret A., Sist P., 2020. Collective and individual interdisciplinarity in a sustainability research group: A social network analysis. Sustainability Science, doi:10.1007/s11625-020-00860-4.

\begin{abstract}
In sustainability science, interdisciplinarity, i.e. the integration of perspectives from different disciplines, is built collectively from interactions among researchers of various disciplines ("collective interdisciplinarity") but also results from the fact that researchers have backgrounds in multiple disciplines ("individual interdisciplinarity"). We applied social network analysis tools to analyze how individual interdisciplinarity influences collective interdisciplinarity, using the case of a forest sustainability science group. We hypothesized that researchers with higher individual interdisciplinarity had more interdisciplinary interactions and were interdisciplinary brokers within the group. We first analyzed individual interdisciplinarity using a bipartite network of researchers and disciplines. We then analyzed networks of management, research, and publication interactions among researchers in the research group. This showed how disciplines influenced interactions and how researchers contributed to interdisciplinary interactions and brokerage. Results of the first analysis identified large disciplinary communities in the center of the bipartite network, whereas smaller ones were more distant. The second analysis highlighted disciplinary homophily in interaction networks, as two researchers interacted more if they were from the same disciplinary community. Results also showed that the interactions among researchers were not only structured by disciplinary homophily, but also by other forms of homophily related to location or region of work. The key brokers of interactions across disciplinary communities were distributed across several communities, showing that brokerage was not controlled by the large, dominant communities. Analysis of correlations between individual interdisciplinarity and contributions to collective interdisciplinarity did not support our hypothesis but rather hinted at the alternative hypothesis that researchers with high individual interdisciplinarity interacted less with other disciplinary communities.
\end{abstract}

\section{Keywords}

interdisciplinarity, science, collaboration, social network analysis, ERGM, homophily, broker 


\section{Introduction}

Emily is a researcher trained in forest ecology who often interacts with other forest ecologists in her research on sustainable forest management. During her studies, she was also trained in geography, which has facilitated her scientific interactions with geographers. In recent years, while working on a large research project on forests and water, she has created strong working relationships with hydrologists and facilitated common work between hydrologists and geographers. Through this fictitious example, we can question how Emily's disciplines have influenced her interactions with other researchers in an interdisciplinary setting and whether Emily or other researchers with multiple disciplinary backgrounds play a special role in connecting scientists from other disciplines.

Science has become increasingly interdisciplinary (Jung et al. 2019; Porter and Rafols 2009). Interdisciplinary research is generally defined by the integration of perspectives from different disciplines (including theoretical frameworks, approaches, and methods) into the study of a common problem (Aboelela et al. 2007a; Wagner et al. 2011). In addition to this general definition, different interpretations of interdisciplinarity have been proposed, depending on what is integrated, how it is done, and why (Huutoniemi et al. 2010). An interdisciplinary research group is made up of researchers who bring knowledge and perspectives from different disciplines and interact among themselves, as well as with other researchers and non-researchers outside the group. The degree of interactions among disciplines makes interdisciplinarity different from multidisciplinarity (where a common question is studied by different disciplines, but without interactions) and transdisciplinarity (where interactions overcome disciplinary boundaries to create an overarching synthesis) (Blanchard and Vanderlinden 2010).

Interdisciplinarity is an important feature of sustainability research, an emerging field of problemoriented research that analyses the interactions between natural and social systems to contribute to a sustainable society (Kates 2011; Komiyama and Takeuchi 2006). Sustainability research is problemoriented and addresses complex issues that must be explored from multiple perspectives sourced from the natural and social sciences (Blanchard and Vanderlinden 2010; Schoolman et al. 2012; van Leeuwen and Tijssen 2000). Examples include research to understand the intertwined ecological, economic, and social dimensions of biodiversity conservation (Bennett et al. 2017) and adaptation to climate change (Fraser et al. 2011). Interdisciplinary collaborations in sustainability research often lead to the transfer of questions or responses from one discipline to another, a phenomenon called interdisciplinarity 'problem feeding' (Schoolman et al. 2012).

Most discussions on interdisciplinarity rely on the idea that interdisciplinarity is collective (Calvert 2010). However, this perspective of interdisciplinarity as a collaboration between disciplinary individuals has been called one of the myths of interdisciplinarity (Molteberg et al. 2000). A different and more marginal perspective considers interdisciplinarity at the individual level, with the notion of researchers possessing several disciplinary skills and integrating perspectives from different disciplines in their work (Wagner et al. 2011). An individual interdisciplinarity can result from an academic education in multiple disciplines or from the experience gained over the course of a career. Future sustainability researchers increasingly follow diversified academic paths, either because they proactively combine different disciplines or because their universities offer courses based on problem-solving rather than on disciplines (Haider et al. 2018; Hein et al. 2018). The outcome of multidisciplinary trainings could be called "individual multidisciplinarity" but we prefer the term "individual interdisciplinarity" because it reflects that the different disciplinary perspectives interact within the mind of a researcher.

The two types of interdisciplinarity, individual and collective, may be dependent on each other. Over time, a research group that is initially interdisciplinary in a collective sense only (with interactions between mono-disciplinary individuals) may influence the behavior of researchers, who may tend to become interdisciplinary at their individual levels after discovering new disciplinary perspectives 
(Calvert 2010). In addition, at a given moment in time, individual and collective interdisciplinarity may also be related, as researchers with several disciplinary perspectives may contribute more to collective interdisciplinarity within a group: they may have more interactions with other disciplines or may facilitate the interactions of researchers of different disciplines (thus playing a broker role) (Molteberg et al. 2000). In addition to the fact that "individual interdisciplinarity is almost never appreciated in academic discussions of interdisciplinarity" (Vojak et al. 2010, p. 546), the relationships between individual and collective interdisciplinarity have not been studied in research groups.

Social network analysis (SNA) is a promising approach for studying scientific interactions or interdisciplinarity (Qin et al. 1997; Yang et al. 2010). Over the past 30 years, SNA has grown from a specialized social science method to a series of techniques applied to multiple fields (Knoke and Yang 2008). The ties analyzed with SNA can represent the fact that researchers work on the same projects, exchange information, or publish together. They can also be ties between research projects or collaborating universities, between journals and disciplines that cite each other, or between entities of a nature different (for example, a researcher and a group) (Biancani and McFarland 2013). Most of the work on SNA applied to research is based on large bibliographic databases, for example, to measure the intensity of interdisciplinarity through citation analysis (Rafols and Meyer 2010) or to analyze how the centrality of researchers in a network influences the number of citations of their publications and the formation of new collaborations (Uddin et al. 2013).

SNAs within small research groups are less common than those based on large bibliographic databases. Some studies analyzed survey data from small research groups to highlight the barriers to interdisciplinary science within a university (Aboelela et al. 2007b) and between universities (Cummings and Kiesler 2005). Survey data on small research groups generally provide detailed information on multiple relationships among researchers, for example, whether a researcher is aware of what another researcher is doing, has met the other, has written a project or a publication with the other, has co-organized an event, or has co-supervised a student (Godley et al. 2013).

In this paper, we apply SNA to a case study of a research group, whose members study forest sustainability science, to test the hypothesis that researchers with high individual interdisciplinarity have more interdisciplinary interactions than those with one discipline, and that they play the role of interdisciplinary brokers within a research group. We address the following questions: What disciplinary communities emerge from the analysis of individual interdisciplinarity? Are there more interactions within disciplinary communities or outside them? How do disciplinary communities and other factors explain the existence of interactions between two scientists? Do brokers connect researchers within their disciplinary communities or across other communities? Do key interdisciplinary brokers in the group belong to specific disciplinary communities? Do researchers with higher individual interdisciplinarity contribute more to interdisciplinary interactions and brokerage? The next two sections first present an analytical framework based on SNA before introducing the studied research group and the detailed methods. The framework is not specifically about sustainability science and could apply to other scientific fields.

\section{A framework for analyzing interdisciplinarity using social network analysis}

We propose two applications of SNA to explore individual and collective interdisciplinarity in small research groups. First, individual interdisciplinarity can be explored with two-mode networks (also called bipartite networks) that represent how researchers identify themselves with different disciplines. Second, one-mode networks can be used to analyze interactions among researchers and to understand how disciplines influence interactions and how researchers contribute to interdisciplinary interactions and brokerage.

The first application uses a bipartite network (i.e. network where ties occur between nodes of different natures) of researchers and disciplines, with ties representing the attachment of 
researchers to disciplines. Analyzing this network can have three purposes. First, we can identify the proximity or distances between disciplines in a research group. For example, if many researchers are attached to both ecology and forestry, these two disciplines can be considered close to each other. Conversely, if almost no one is attached to ecology and sociology at the same time, these disciplines may be considered distant. This idea has been applied previously to large datasets of crossdisciplinary citations to assess the dissimilarities (Wang et al. 2015) or the 'intellectual distances' between disciplines (Van Noorden 2015 , p. 306). Second, the distance between disciplines (quantifiable by different network measures) can help in assessing the individual interdisciplinarity of researcher. For example, a researcher who combines sociology and ecology could be considered more interdisciplinary than a researcher who combines ecology and forestry. Several measures can be used to assess this individual interdisciplinarity (see Methods section). Third, the bipartite network can be used to identify disciplinary communities, i.e. sets of disciplines and researchers having stronger attachment ties within a community than between communities.

The second application uses interaction networks, which represent how researchers share information, conduct fieldwork or management tasks together, or co-author publications for example. Analysis of interaction networks has three objectives. We can first analyze whether interactions occur within or across disciplinary communities, which sheds light on the proneness to disciplinary homophily. Homophily is an important topic of SNA that relates to the fact that people who are alike interact more easily (McPherson et al. 2001). Disciplinary homophily can drive the exchange of information between researchers and constrain interdisciplinarity (McPherson et al. 2001). For example, one study showed that, during coffee breaks at research retreats, the interactions between doctoral students reflected a high degree of homophily of institutions and research subjects (Kibanov et al. 2019).

Second, the analysis of interaction networks can go beyond disciplinary homophily and analyze other factors that explain the occurrence of an interaction between a pair of researchers; such homophily can be related to geographic location or social status. For example, a study found that collaborations were more frequent between two researchers located in the same geographic region but not between two researchers at the same hierarchical level in their institutions or with the same level of prestige (Binz-Scharf et al. 2015). In addition, individual factors can also explain the existence of interactions, for example, scientific reputation and research seniority (Van Rijnsoever and Hessels 2011). It is thus important to factor out the effect of individual factors or other forms of homophily before concluding on disciplinary homophily.

Third, the analysis of interaction networks can identify the key researchers with interdisciplinarity in the group, i.e. those who work the most with researchers from other disciplinary communities and those who connect researchers from other disciplinary communities (the so-called brokers). Broker analysis is important in SNA, for example, it helps identify how to better coordinate policy actions (Locatelli et al. 2020) or how to fill gaps in the interfaces between science and society (Neal et al. 2019). To better understand the role of brokers in interdisciplinarity, we propose to adjust and simplify Gould and Fernandez' (1989) typology, as it was not initially developed for interdisciplinarity (Fig. 1a). The adjusted typology used in our study distinguishes different brokerage roles depending on whether brokers connect researchers from their disciplinary community or from other communities (Fig. 1b): brokers can be disciplinary coordinators (between researchers from their own disciplinary community), interdisciplinary boundary spanners (between members of their disciplinary community and members outside their community), and interdisciplinary bridges (between members of other communities). 


\section{a. Gould and Fernandez' brokerage types in transaction networks}

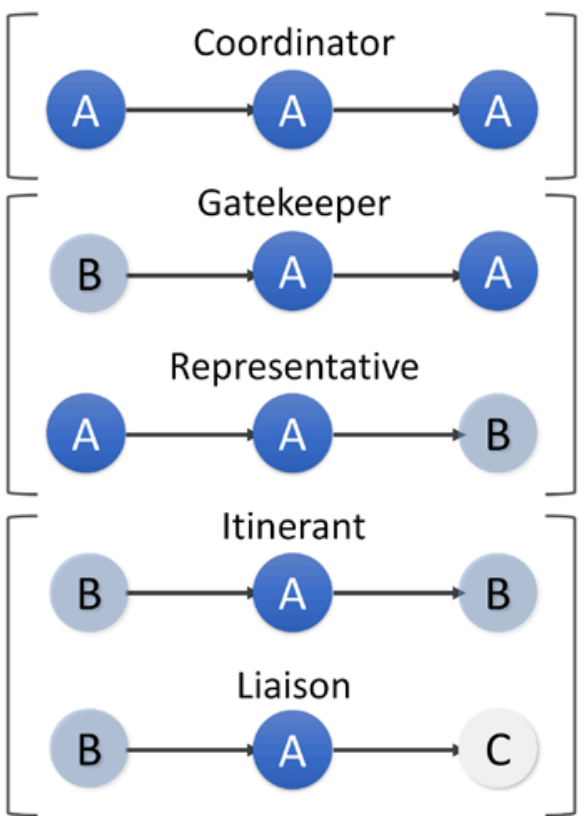

\section{b. Role of brokers in} interdisciplinary research

Disciplinary coordinator

The broker connects research within his/her own disciplinary community

Interdisciplinary

boundary spanner

The broker connects one person within his/her own disciplinary community with one person outside

Interdisciplinary bridge

The broker connects people outside of his/her own disciplinary community

Figure 1. Our proposed typology of disciplinary brokerage roles. The circles represent researchers identified by their disciplinary communities $(A, B, C)$. Broker typology at the left is from Gould and

Fernandez (1989) and applies to a directed network (for undirected ones, gatekeeper and representative are identical). 'Boundary spanner' and 'bridge' are terms taken from Long et al. (2013)

\section{Materials and methods}

\section{The research group}

A SNA was applied to the "Forests and Societies" research group of the French Agricultural Research Centre for International Development (CIRAD). The research group works on the sustainable management of tropical forest ecosystems and the contributions of tropical forests to human wellbeing. Researchers study tropical forests as social-ecological systems and aim to understand the adaptation of these systems to global changes and the sustainability of the ecosystem services provided by tropical forests at local, regional, and global scales. Like in other sustainability science groups, the scientists of the group are interested in multiple interdisciplinary items, such as ecosystems, social groups, or policies, and apply diverse disciplinary approaches (from ecology, geography, and the social, economic, or political sciences, among others).

One of the characteristics of this group is that staff are multi-localized, with scientists based at the headquarters in Montpellier (France) or out-posted in Africa, Asia, Latin America, and Europe (outside of Montpellier). The target population for this analysis was the 41 researchers with permanent positions on November 1, 2018 who had been in the group for more than a year. This one-year threshold was chosen as the time necessary for newcomers to integrate and build interactions. The sample analyzed was made up of the 39 researchers from this population who answered a survey (i.e. $95 \%$ of the population).

\section{Data collection}

Basic data on the researchers were collected from existing sources (CIRAD Human Resources database, Google Scholar) and a key informant in the group (its director) and by asking all 
researchers to complete an online survey (Table 1). The data related to the activities over approximately four years (2015-2018, which corresponds to the four-year planning and evaluation phase of the group), except for seniority or citation indices which were measured at the end of 2018 .

Table 1. Variables describing researchers and potentially predicting interactions among researchers

\begin{tabular}{|c|c|c|}
\hline Variable & Values & Data source \\
\hline $\begin{array}{l}\text { Seniority (measured with the } \\
\text { number of years in the group) }\end{array}$ & $\begin{array}{l}\text { Min 6, Median 19, Max } 40 \text { (0-1 normalized for the } \\
\text { analysis) }\end{array}$ & Human Resources database \\
\hline $\begin{array}{l}\text { Recognition (measured with } \\
\text { the } \mathrm{H} \text {-index, a citation index) }\end{array}$ & $\begin{array}{l}\text { Min 1, Median 13, Max } 33 \text { (0-1 normalized for the } \\
\text { analysis) }\end{array}$ & $\begin{array}{l}\text { Individual profiles in Google } \\
\text { Scholar or in the software } \\
\text { "Publish or Perish" based on } \\
\text { Google Scholar data }\end{array}$ \\
\hline $\begin{array}{l}\text { Leadership (of a large research } \\
\text { project in the group) }\end{array}$ & Yes $(n=15)$, No $(n=24)$ & \multirow[t]{3}{*}{ Key informant in the group } \\
\hline $\begin{array}{l}\text { Committee member (the } \\
\text { management committee is a } \\
\text { rotating group of four people, } \\
\text { including the group director, } \\
\text { making managerial decisions) }\end{array}$ & Yes $(n=8)$, No $(n=31)$ & \\
\hline $\begin{array}{l}\text { Location at headquarters in } \\
\text { Montpellier (France) during } \\
\text { part or all the period of } \\
\text { analysis }\end{array}$ & Yes $(n=24)$, No $(n=15)$ & \\
\hline Regions of work & $\begin{array}{l}\text { Central Africa ( } n=28) \text {, Amazon Basin (17), West Africa } \\
(n=16) \text {, Southeast Asia }(n=15) \text {, Indian Ocean }(n=11) \text {, } \\
\text { Central America and Mexico }(n=9) \text {, East Africa }(n=9) \text {, } \\
\text { Southern Africa }(n=8) \text {, South Asia }(n=5) \text {, Caribbean }(n=5) \text {, } \\
\text { Europe }(n=3) \text {, Central Asia }(n=3) \text {, Andes }(n=2) \text {, Oceania } \\
(n=1)\end{array}$ & \multirow[t]{2}{*}{$\begin{array}{l}\text { Online survey to } \\
\text { researchers }\end{array}$} \\
\hline Disciplines & $\begin{array}{l}\text { Disciplines to which the researcher feels attached (main } \\
\text { discipline, and optionally, secondary or tertiary } \\
\text { discipline) (see details in the text) }\end{array}$ & \\
\hline
\end{tabular}

For the disciplines, we consulted the Human Resources database and asked each researcher individually to verify and correct their personal data. The database included the main discipline that a researcher felt attached to, and optionally, a secondary or tertiary discipline that the researcher could select (see full list in Fig. 2). The following disciplines were grouped or renamed for the analysis: anthropology (renamed from "anthropology-ethnology" in the database), statistics and applied mathematics (merging three disciplines of the database: statistics, scientific calculus and simulation, mathematical modeling of complex systems), ecology (merging community ecology, population ecology, functional ecology), computing (merging information systems, computing and software engineering), and economics (merging macroeconomics, mesoeconomics, microeconomics).

For the interactions within the group, we asked researchers to nominate who they had interacted with during the last four years. We considered three forms of interactions: management (e.g. interactions to promote internal exchanges, seek funding, set up new projects, manage projects, create new partnerships outside the group, manage collective activities, or implement an item of collective research infrastructure such as a shared database), research (e.g. interactions to develop research questions, discuss literature, exchange data, discuss methods, apply tools, collect data, do fieldwork together, analyze data, and supervise students), and publication (in the broad sense of disseminating research results, e.g. interactions to co-author papers, prepare or present a communication at a conference, or organize an outward-looking scientific event). 


\section{Data analysis}

The first step of the analysis dealt with researchers' disciplinary attachments. We built a bipartite network, in which researchers and disciplines were connected through weighted ties representing the strength of the disciplinary attachment. The attachment strength came from the data provided by researchers: we attributed a strength of $1,0.7$, and 0.4 to the attachment between a researcher and his or her main, secondary, and tertiary disciplines, respectively, and, because researchers reported different numbers of disciplines with different attachment strengths, weights were normalized so that the total of the weights was 1 for each researcher.

The bipartite network (as well as the interaction network later) was graphically represented using the Fruchterman-Reingold algorithm, which ensures that nodes with strong ties are located close to each other (layout_with_fr with the igraph package in R) (Csardi 2018). An algorithm called Fast Greedy was applied to the bipartite network to automatically detect communities, i.e. sets of researchers and disciplines that have more ties with each other than with the rest of the network (Csardi 2018). This method helped identify disciplinary communities of researchers, easily named from the disciplines included in the communities. For each researcher, we also calculated the values of three indicators of individual interdisciplinarity (Table 2).

Table 2. Indicators of individual interdisciplinarity, inspired by Rafols and Meyer (2010)

\begin{tabular}{|c|c|c|c|}
\hline Name & Meaning & Measure & Equation \\
\hline Variety & Number of distinct disciplines of a researcher & Count & $\sum_{i \in E_{r}} 1$ \\
\hline Balance & $\begin{array}{l}\text { Evenness of the attachment of a researcher to his/her } \\
\text { disciplines }\end{array}$ & Shannon index & $-\sum_{i \in E_{r}} p_{r i} \ln p_{r i}$ \\
\hline Disparity & Degree to which the disciplines of a researcher are distant & Stirling index & $\sum_{i, j \in E_{r}} d_{i j} p_{r i} p_{r j}$ \\
\hline \multicolumn{4}{|c|}{ 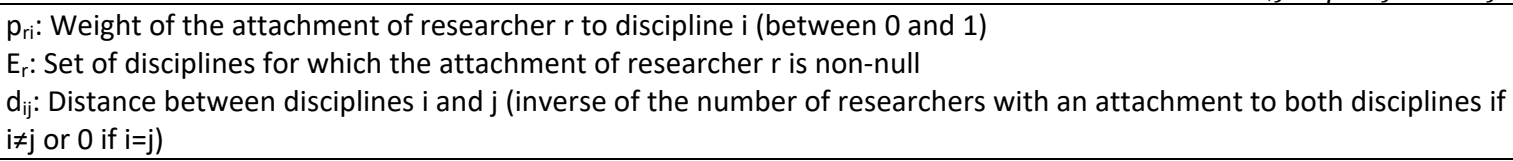 } \\
\hline
\end{tabular}

In a second step, we built four unweighted networks representing the interactions between researchers regarding management, research, publication, and all forms of interactions (i.e. the union of the first three networks). For this, we first symmetrized the data on interactions, considering that two researchers interacted if at least one of them mentioned their interaction. To analyze disciplinary homophily, we calculated an interdisciplinarity index for each disciplinary community, an approach related to the E-I index (Krackhardt and Stern 1988). Our index was simply the ratio of interactions of this community that occur with other communities. To assess whether the interdisciplinarity index of a community was unexpectedly low or high, we compared it with the values of this index after randomly permuting disciplinary communities. We simulated 100,000 networks by permuting the disciplinary communities and obtained a distribution of the expected values of the index for each community and the probability that the observed value was lower or higher than the expected value.

In a third step, we analyzed the factors influencing the existence of interactions between researchers using exponential random graph models (ERGMs), developed specifically for this purpose (Robins and Lusher 2013b). The existence of ties could have been explained by simpler statistical models, for example, log-linear models that relate the existence of a tie between two actors to the characteristics of the actors. However, such models assume that observations are independent, which is not the case for the ties within a social network. For example, because of transitivity, a common feature of real-life social relationships, the existence of a tie from $A$ to $B$ depends on whether A and B have a tie to a third actor C (Lusher and Robins 2013). These structural 
effects are a strength of ERGMs, and they prevent the misestimation of other effects (Cranmer and Desmarais 2011). Ties in an ERGM can be explained by different kinds of effects, including structural (e.g. transitivity), actor level (e.g., the age of an actor), dyadic level (e.g. the fact that the two actors on either side of the tie are similar, i.e. they exhibit homophily), and relational (e.g. the fact that the two actors on either side of the tie are also tied in other networks) (Robins and Lusher 2013a). Variables at actor level included seniority, recognition, project leadership, and participation in management committee (gender was also tested but discarded because it had no significant effects in any analysis). We fitted the ERGMs using a Markov chain Monte Carlo simulation and applied diagnostic tools and goodness-of-fit analysis to check whether the models were good representations of the observed network (Butts et al. 2015) (details in Supplementary Material SM2). All calculations were made in R (R Core Team 2018) with the ergm package, part of the statnet suite (Handcock et al. 2016).

In a fourth step, we identified key brokers in the four interaction networks and their brokerage roles (Coordinator, Spanner, Bridge, see Fig. 2). Using the brokerage function in the sna package in $R$ (Butts 2016), we calculated the brokerage scores of all researchers, that is, the numbers of pairs that a particular researcher has ties to that are not directly connected. The scores were computed separately for each brokerage role and compared to the expected values to assess whether observed values differed significantly from expected ones (the brokerage function estimates expectations and variances of the scores, as well as approximate z-test results).

In a final fifth step, we explored the Pearson correlations between the three indicators of individual interdisciplinarity previously calculated and eight indicators of contribution to collective interdisciplinarity. This highlighted interdisciplinary interactions (percentage of relationships that the researcher had with researchers from other disciplinary communities) and interdisciplinary brokerage (total brokerage score for interdisciplinary broker role) for the four interaction networks (management, research, publication, and all). The indicators of contribution to collective interdisciplinarity were used in a standardized form (difference between observed and expected value, divided by the standard deviation). We also observed the correlations between researcher characteristics and individual interdisciplinarity or contributions to collective interdisciplinarity. 


\section{Results}

\section{Researchers' disciplinary attachments}

Surveyed researchers reported their attachments to 17 disciplines, with most reporting more than one discipline ( $n=3$ for one discipline, $n=19$ for two disciplines, $n=17$ for three disciplines). The most frequent disciplines were forestry, ecology, and geography with 12 or more researchers. The community detection algorithm found six disciplinary communities in the bipartite network of researchers tied to disciplines (see colors in Fig. 2). Three large disciplinary communities (forest sciences, ecological sciences, and spatial sciences, with eight or more researchers) occupied the core of the network, while there were three smaller ones in the periphery (computer sciences, economic and political sciences, and social sciences, with four or fewer researchers, Fig. 2).

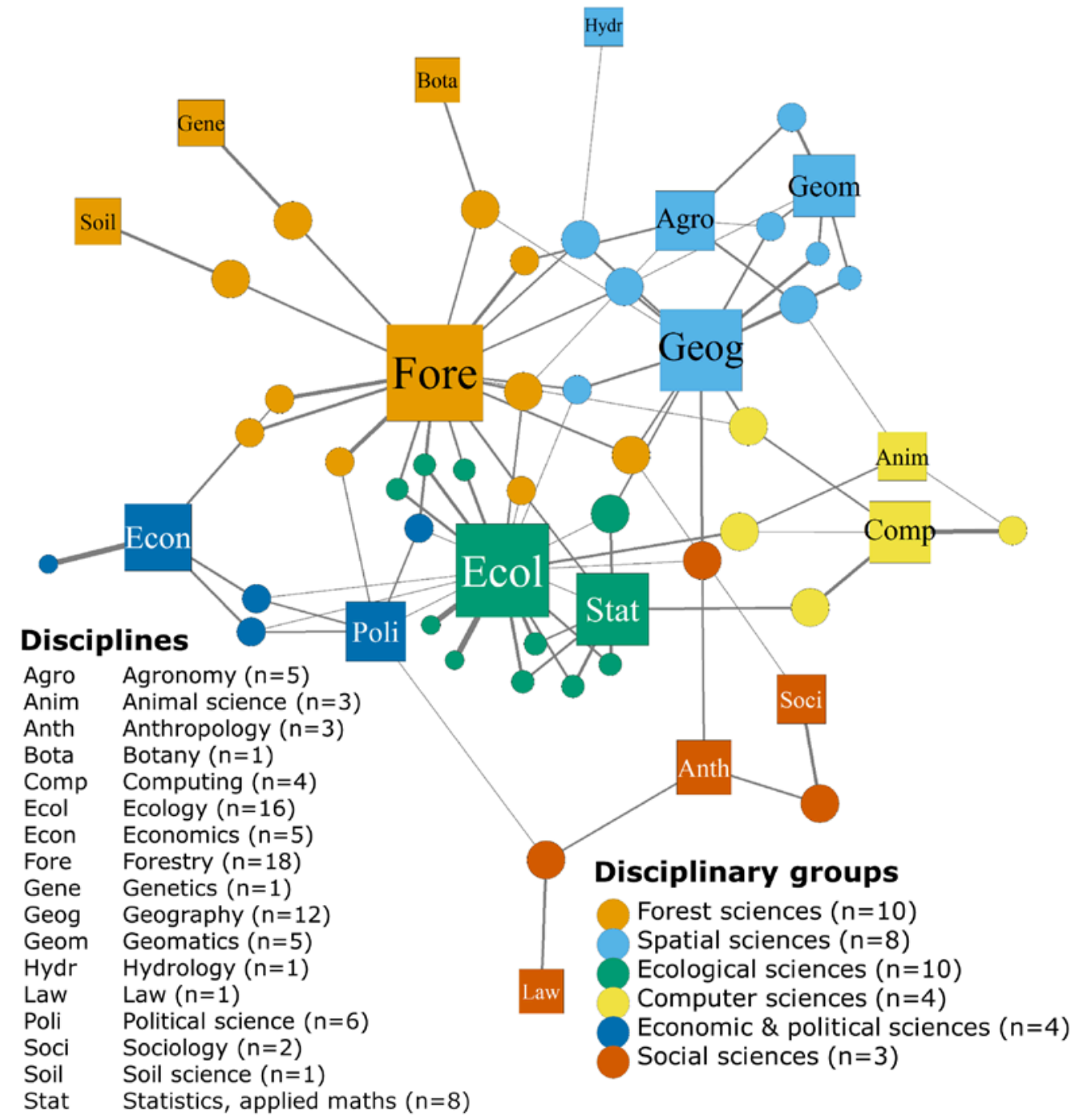

Figure 2. Bipartite network showing researchers (circles), disciplines (squares), and ties between them (i.e. disciplinary attachment reported by researchers). The width of a square depends on the number of researchers attached to the discipline. The width of a circle depends on the interdisciplinarity index of the researcher (defined in the text). The width of a tie represents the strength of the attachment of a researcher to a discipline. The colors show the disciplinary communities identified by a community detection algorithm 


\section{Homophily within disciplinary communities}

Some disciplinary homophily was suggested by the representation of the network of all interactions (Fig. 3) (see basic descriptors of the four networks in Supplementary Material SM1). Indeed, the algorithm used to display the network layout positions researchers close together if they have strong ties between them (Fig. 3). Thus, the clustering of researchers according to colors (i.e. disciplinary communities) suggested strong interactions within communities (for example, the ecological sciences occupy one part of the figure, and the forest sciences occupy another).

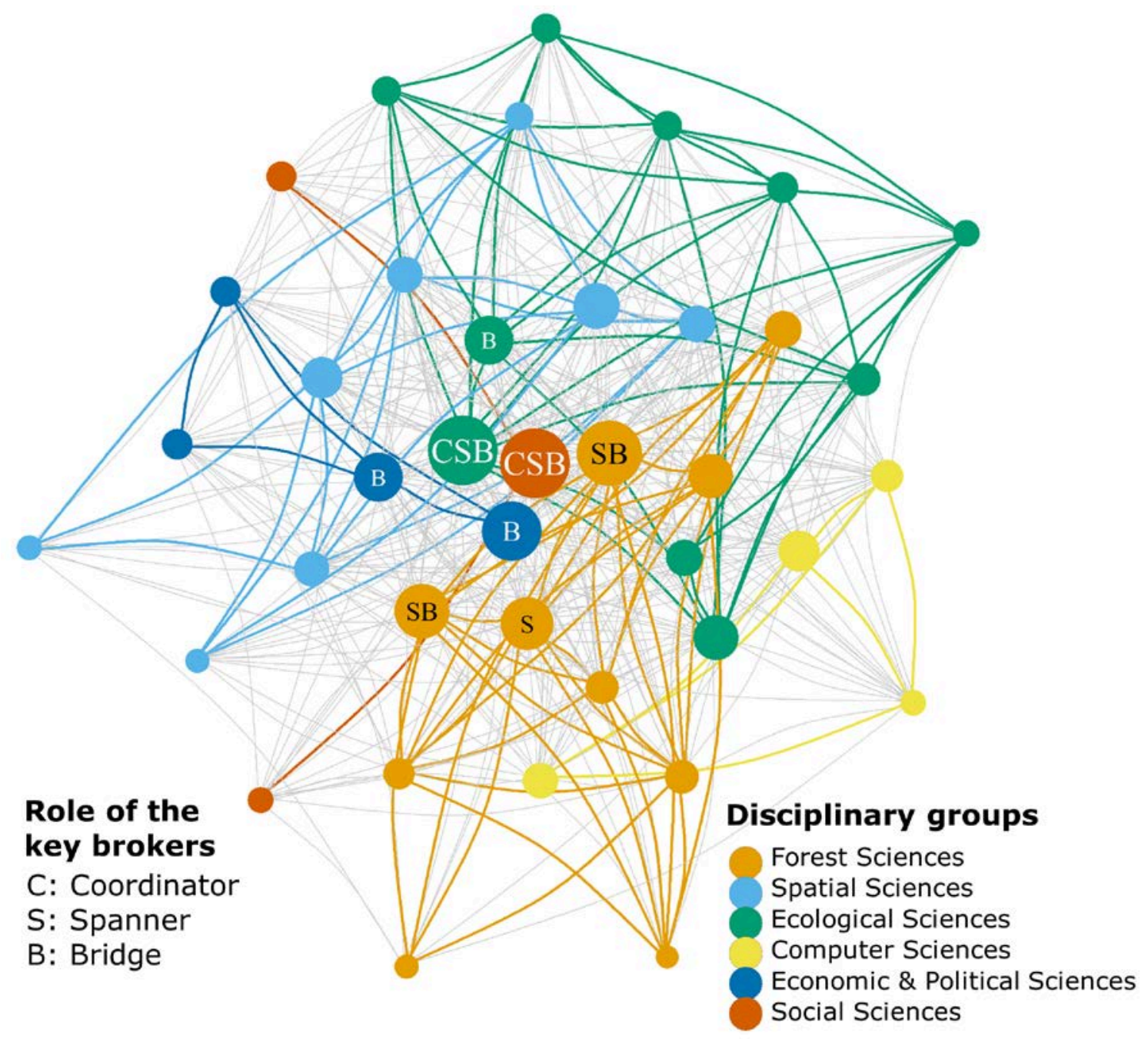

Figure 3. Network representation of the interactions (of any form) among researchers. Researchers are represented by circles (color indicates the disciplinary community and size indicates the total standardized brokerage score). Interactions between researchers are represented by colored ties if they occur within disciplinary communities (and are gray otherwise). The key brokers are identified by a label describing their role 
This suggested disciplinary homophily was confirmed by statistical analyses (Table 3 ): for most disciplinary communities and forms of interactions, there were significantly fewer interactions outside the community than expected, which meant that disciplinary communities facilitated interactions within them. This was particularly true for publication interactions, which were stronger than expected within all disciplinary communities.

Table 3. Ratio of interactions that take place outside of the disciplinary community (as a measure of interdisciplinary interactions). The observed values are compared with the distribution of expected values calculated with a random permutation of disciplinary communities (*** for $p<0.001,{ }^{* *}$ for $p<$

0.01 , and * for $p<0.05$, " $n s$ " for not significant at $p=0.05$ ). Here, for all significant differences, observed values were lower than expected

\begin{tabular}{|c|c|c|c|c|c|}
\hline \multirow[t]{2}{*}{ Disciplinary community } & \multirow[t]{2}{*}{ Expected ratio } & \multicolumn{4}{|c|}{ Observed ratio (and statistical significance) } \\
\hline & & $\begin{array}{l}\text { Management } \\
\text { interactions }\end{array}$ & $\begin{array}{l}\text { Research } \\
\text { interactions }\end{array}$ & $\begin{array}{l}\text { Publication } \\
\text { interactions }\end{array}$ & $\begin{array}{l}\text { All } \\
\text { interactions }\end{array}$ \\
\hline Forest sciences & $0.765( \pm 0.026)$ & $0.695(* * *)$ & $0.660(* * *)$ & $0.629(* * *)$ & $0.692(* * *)$ \\
\hline Spatial sciences & $0.817( \pm 0.026)$ & $0.763(* *)$ & 0.787 & $0.696(* * *)$ & 0.784 \\
\hline Ecological sciences & $0.765( \pm 0.026)$ & $0.725\left(^{*}\right)$ & 0.733 & $0.648(* * *)$ & 0.728 \\
\hline Computer sciences & $0.923( \pm 0.023)$ & 0.914 & $0.850(* * *)$ & $0.875(* *)$ & $0.879(* *)$ \\
\hline $\begin{array}{l}\text { Economic \& political } \\
\text { sciences }\end{array}$ & $0.923( \pm 0.023)$ & 0.910 & $0.888(*)$ & $0.875(* *)$ & 0.907 \\
\hline Social sciences & $0.949( \pm 0.022)$ & 0.938 & $0.90(* *)$ & $0.895(* * *)$ & 0.946 \\
\hline
\end{tabular}




\section{Factors explaining interactions between researchers}

Disciplinary homophily was confirmed at the level of interactions between pairs of researchers by the ERGMs (Fig. 4): two researchers in the same disciplinary community were more likely to interact than others, particularly for research and publication interactions. There were, however, other forms of homophily: whereas the strongest homophily in publication was disciplinary, the strongest homophily in research and management came from work regions, such that sharing the same region of work increased these forms of interactions. Another form of homophily was related to researcher locations: two researchers based at headquarters were more likely to interact, particularly for management, which is mostly centralized at headquarters. The interactions were also influenced by individual characteristics (e.g. recognized researchers had more research and publication interactions, or researchers who had led large projects had more management and research interactions) but to a lesser extent than the various forms of homophily (Fig. 4).

\begin{tabular}{|c|c|c|c|c|c|}
\hline Group of effects & Effect & $\begin{array}{l}\text { Management } \\
\text { interactions }\end{array}$ & $\begin{array}{l}\text { Research } \\
\text { interactions }\end{array}$ & $\begin{array}{l}\text { Publication } \\
\text { interactions }\end{array}$ & $\begin{array}{l}\text { All } \\
\text { interactions }\end{array}$ \\
\hline \multirow{3}{*}{ Structural } & $\begin{array}{l}\text { Edges (Baseline effect, similar } \\
\text { to intercept in linear models) }\end{array}$ & $-170(47)^{* * *}$ & $3.4(2.8)$ & $-3.9(0.64) * * *$ & $-430(300)$ \\
\hline & $\begin{array}{l}\text { Transitivity (Number of } \\
\text { shared partners) }\end{array}$ & $99(29) * * *$ & $0.68(1.6)$ & $0.72(0.31) *$ & $260(180)$ \\
\hline & $\begin{array}{l}\text { Disciplinary homophily (Researchers are } \\
\text { in the same disciplinary community) }\end{array}$ & \begin{tabular}{|c}
$\longrightarrow$ Effect \\
$\stackrel{4}{* * *}$ \\
$0.71(0.20)$
\end{tabular} & 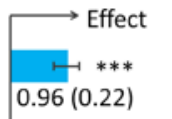 & $1.0(0.20)$ & \begin{tabular}{|l} 
Effect \\
\\
$1.1(0.26)$
\end{tabular} \\
\hline \multirow{4}{*}{$\begin{array}{l}\text { Dyadic } \\
\text { level } \\
\text { (characteristics } \\
\text { of pairs of } \\
\text { researchers) }\end{array}$} & HQ location homophily (Researchers have & - & - & $H * * *$ & $\mapsto$ \\
\hline & both & $1.1(0.21)$ & $0.71(0.19)$ & $0.63(0.19)$ & $1.3(0.23)$ \\
\hline & $\begin{array}{l}\text { Work region homophily (Researchers } \\
\text { work in one or more common regions) }\end{array}$ & $1.2(0.20)$ & $P^{-1.4 * *}$ & $\begin{array}{l}1-1 * * * \\
0.75(0.21)\end{array}$ & $1.4(0.20)$ \\
\hline & $\begin{array}{l}\text { Recognition (Researcher has a high } \\
\text { citation score) }\end{array}$ & $0.31(0.25)$ & $1.0(0.26)$ & 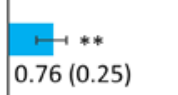 & $0.18(0.28)$ \\
\hline \multirow{3}{*}{$\begin{array}{l}\text { Researcher } \\
\text { level } \\
\text { (characteristics } \\
\text { of a researcher } \\
\text { at either side of } \\
\text { the tie) }\end{array}$} & $\begin{array}{l}\text { Seniority (Researcher has spent many } \\
\text { years in the group) }\end{array}$ & $\begin{array}{l}* * * \\
-0.81(0.24)\end{array}$ & $-0.39(0.23)$ & $-0.24(0.24)$ & $\begin{array}{l}* * * \\
-1.1(0.26)\end{array}$ \\
\hline & $\begin{array}{l}\text { Leadership (Researcher has led a large } \\
\text { research project) }\end{array}$ & $\begin{array}{l}F * * \\
0.48(0.18)\end{array}$ & $\begin{array}{l}1-4 * \\
0.49(0.19)\end{array}$ & $0.24(0.18)$ & $0.51(0.21)$ \\
\hline & $\begin{array}{l}\text { Committee (Researcher has been in the } \\
\text { management committee) }\end{array}$ & \begin{tabular}{|c|c|}
$-7 * *$ \\
$0.76(0.15)$
\end{tabular} & $\begin{array}{ll}H * \\
0.35(0.15)\end{array}$ & $F_{0.17(0.14)}^{-1}$ & $\begin{array}{c}1-1 * * \\
0.90(0.17)\end{array}$ \\
\hline
\end{tabular}

Figure 4. Results of the four ERGMs explaining four forms of interactions (which can be interpreted similarly to the results of a linear model). Effect estimates and standard errors are represented by bar plots (blue for a positive effect, red for a negative) and error bars for the dyadic and researcher levels (significance: ${ }^{* *}$ for $p<0.001,{ }^{* *}$ for $p<0.01$, and ${ }^{*}$ for $p<0.05$ ).

\section{Brokers across disciplinary communities}

Eight researchers had particularly high brokerage scores, which were significantly higher than the expected scores in the network of all interactions. It meant that they interacted with many pairs of researchers who were not directly interacting. These key brokers (who appear in the center of the network representation in Fig. 3) belonged to disciplinary communities of any size (five belonged to large communities, three to small). The key brokers played mostly interdisciplinary roles: seven were interdisciplinary bridges and five were interdisciplinary boundary spanners, while only two were disciplinary coordinators. Two key brokers played the three roles, one from a small disciplinary community (social sciences) and the other from a large one (ecological sciences). 


\section{Correlations between individual and collective interdisciplinarity}

People with more individual interdisciplinarity contributed less to collective interdisciplinarity. All three indicators of individual interdisciplinarity were negatively corrected to the contribution to interdisciplinary interactions in management and research, but not in publication (Fig. 5). Indicators of individual interdisciplinarity were not significantly correlated to indicators of contribution to interdisciplinary brokerage or the total number of interactions in any network.

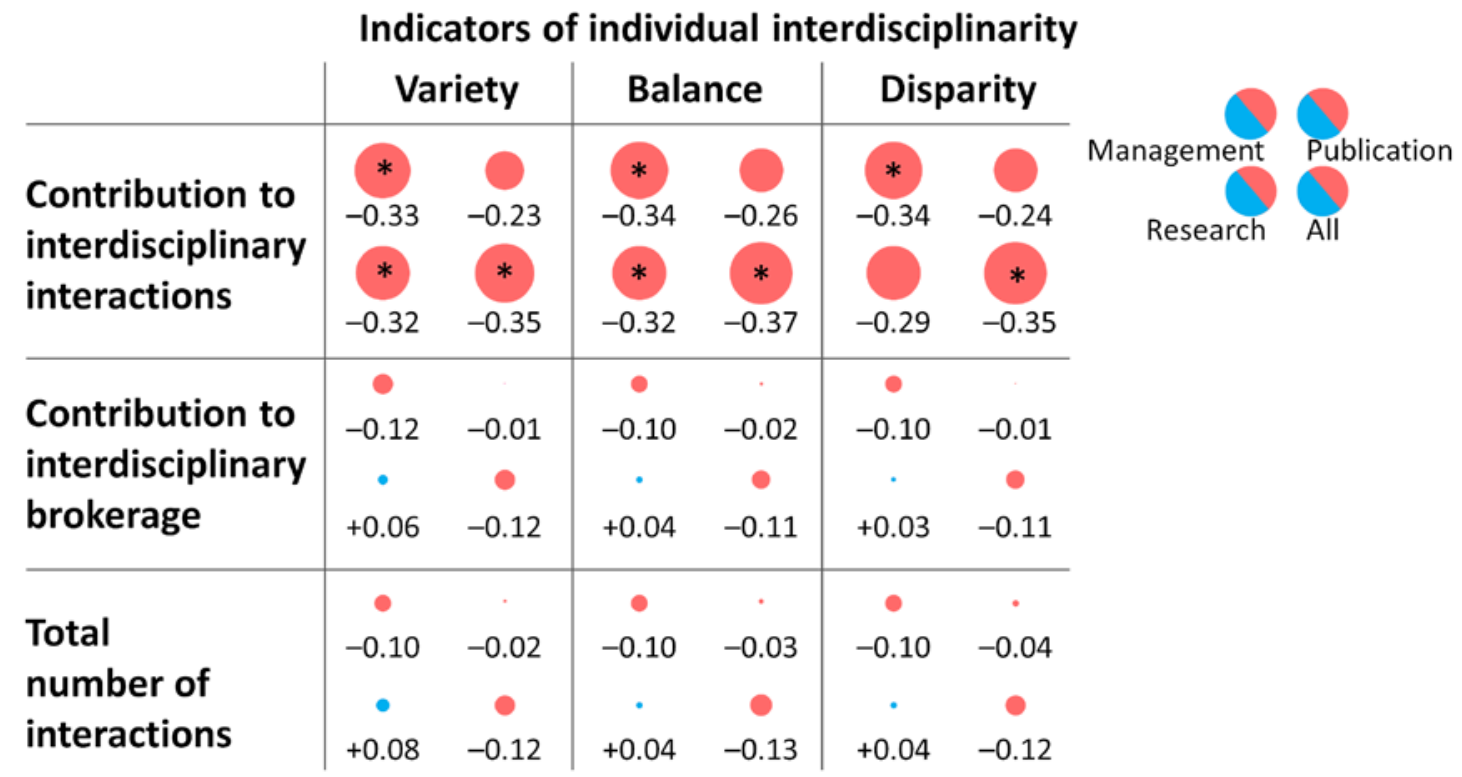

Figure 5. Pearson correlations among three indicators of individual interdisciplinarity (variety, balance, and disparity) and two indicators of contribution to collective interdisciplinarity (interdisciplinary interactions and brokerage), and the total number of interactions in the four forms of interactions. The diameters of the circles are proportional to the absolute correlations, their colors depend on the signs (blue for positive, red for negative), and the significance levels are shown inside the circles (*: $p<0.05)$. 


\section{Effect of researcher characteristics}

Some researcher characteristics were correlated to their role in interdisciplinarity. Researchers with more recognition contributed more to interdisciplinary brokerage in publications. Leaders of large projects contributed more to interdisciplinary brokerage in research. Members of the management committee contributed more to interdisciplinary brokerage in all types of interactions. The seniority of researchers had no significant effect on the contribution to collective interdisciplinarity. No characteristic of the researchers influenced individual interdisciplinarity (Fig. 6).

\begin{tabular}{|c|c|c|c|c|c|c|c|c|}
\hline \multirow[b]{3}{*}{$\begin{array}{l}\text { Contribution to } \\
\text { interdisciplinary } \\
\text { interactions }\end{array}$} & \multicolumn{7}{|c|}{ Researcher characteristics } & \\
\hline & \multicolumn{2}{|c|}{ Recognition } & \multicolumn{2}{|c|}{ Seniority } & \multicolumn{2}{|c|}{$\begin{array}{l}\text { Project } \\
\text { Leader }\end{array}$} & $\begin{array}{c}\text { Management } \\
\text { Committee }\end{array}$ & \\
\hline & $\begin{array}{c}\cdot \dot{\cdot} \\
+0.04 \\
+ \\
+0.07\end{array}$ & $\begin{array}{c}\bullet \\
+0.10 \\
\bullet \\
+0.07\end{array}$ & $\begin{array}{c}\bullet \\
+0.15 \\
-0.16 \\
\end{array}$ & $\begin{array}{l}\cdot \\
+0.07 \\
+0.01\end{array}$ & $\begin{array}{c}0.24 \\
+0.09 \\
+0.09\end{array}$ & $\begin{array}{c}+0.26 \\
+0.23 \\
\end{array}$ & \begin{tabular}{cc}
$\bigcirc$ & $\bullet$ \\
+0.29 & +0.12 \\
\hdashline & $\bigcirc$ \\
+0.13 & +0.27 \\
\end{tabular} & Management Publication \\
\hline $\begin{array}{l}\text { Contribution to } \\
\text { interdisciplinary } \\
\text { brokerage }\end{array}$ & +0.08 & $\begin{array}{c}* \\
+0.35 \\
\bullet \\
+0.07\end{array}$ & $\begin{array}{c}\bullet \\
-0.10 \\
+ \\
+0.02 \\
\end{array}$ & $\begin{array}{c}+0.01 \\
-0.12\end{array}$ & $\begin{array}{c}\bullet \\
+0.15 \\
* \\
+0.32 \\
\end{array}$ & $\begin{array}{c}0.27 \\
+0 \\
+0.13\end{array}$ & $\begin{array}{cc}+0.48 & +0.37 \\
* & * \\
+0.39 & +0.47 \\
\end{array}$ & \\
\hline $\begin{array}{l}\text { Individual } \\
\text { interdisciplinarity: } \\
\text { Variety }\end{array}$ & & & & 0.10 & & +0.03 & -0.19 & \\
\hline $\begin{array}{l}\text { Individual } \\
\text { interdisciplinarity: } \\
\text { Balance }\end{array}$ & & & & 0.08 & & $\begin{array}{c}\cdot \\
+0.04\end{array}$ & -0.25 & \\
\hline $\begin{array}{l}\text { Individual } \\
\text { interdisciplinarity: } \\
\text { Disparity }\end{array}$ & & & & .13 & & +0.02 & -0.25 & \\
\hline
\end{tabular}

Figure 6. Pearson correlations between four researcher characteristics and two indicators of contribution to collective interdisciplinarity (interdisciplinary interactions and brokerage) in the four forms of interactions (Research, Management, Publication, and All, counterclockwise from the bottom left in each cell), and three indicators of individual interdisciplinarity (variety, balance, and disparity). The diameters of the circles are proportional to the absolute correlations, their colors depend on the signs (blue for positive, red for negative), and the significance levels are shown inside the circles (*: $p<0.05)$. 


\section{Discussion}

We have analyzed individual and collective interdisciplinarity in a research group using SNA tools. We tested the hypothesis that researchers with high individual interdisciplinarity had more interdisciplinary interactions or were interdisciplinary brokers in the group. With a bipartite network tying researchers to disciplines, we identified disciplinary communities and calculated indicators of individual interdisciplinarity. The networks of interactions between researchers showed clear disciplinary homophily, along with other forms of homophily. Key brokers of interactions across disciplinary communities came from different disciplinary communities, either small or large. The analysis of correlations between individual interdisciplinarity and contribution to collective interdisciplinarity did not support our hypothesis, but rather hinted at the alternative hypothesis that researchers with high individual interdisciplinarity had fewer interdisciplinary interactions.

\section{Individual attachments to disciplines}

The bipartite network tying researchers to disciplines clearly revealed the disciplinary diversity of the research group studied. The presence of three large disciplinary communities at the core of the network representation comes from the fact that many members of the research group are attached to the disciplines included in these communities. The network representation questions the place of the three small disciplinary communities and the way in which these communities are inserted into the group, even though the positions of the disciplinary communities in the core or the periphery do not presume interactions between researchers but only reflect the proximity between disciplines. We see disciplinary communities that are isolated and probably have little commonality with many researchers in the group.

The observed distances between disciplines in the network representation are generally aligned with common sense or the global maps of science that represent disciplines as networks (Leydesdorff and Rafols 2009): for example, law and botany or sociology and soil science appear distant in this specific research group, whereas forestry and ecology are close. However, some proximities (e.g. between animal sciences and computing) are peculiarities of this small group analysis and would not appear in an analysis over a broader group. To avoid these peculiarities, large datasets of citations could be used for a better analysis of distances between disciplines (Boyack and Klavans 2014).

In our analysis, the vast majority of researchers felt attached to more than one discipline. This result can be explained by the research carried out by this group, because problem-oriented sustainability research attracts scientists with multidisciplinary training or incentivizes researchers to adopt new disciplinary perspectives (Hackenburg et al. 2019). The attachment of researchers to multiple disciplines can also be a bias of the data collection method, as researchers were explicitly invited to identify more than one discipline, which may have exaggerated their multidisciplinarity. Another bias may have originated from how researchers interpreted the idea of an attachment to a discipline, as attachment may correspond to diverse realities, for example, a degree received after several years of studies in the discipline, a minor (i.e. a secondary set of courses in a discipline that differs from the main discipline), an autodidactic learning of a new discipline, or perhaps only a special interest in a discipline. In addition, disciplinary affiliations may sometimes blur for researchers who have spent years studying subjects that are very interdisciplinary in nature (Schummer 2004). Finally, another explanation can be that some disciplines have fuzzy boundaries (e.g., forestry) and that researchers from these disciplines may feel also attached to neighbor disciplines. It has been suggested that this fuzziness may benefit interdisciplinarity, as disciplines with fuzzy boundaries 'appear to be hospitable to extensive growth at the edges of their territory' (Davis 1992 , p. 178).

This analysis of the disciplinary structure can only work if the majority of researchers identify themselves with several disciplines. In the extreme case in which all researchers feel attached to single disciplines, the bipartite network would include several sub-graphs disconnected from each other, each one grouping together a discipline and the researchers within this discipline. Therefore, 
analyzing disciplinary communities would not make sense as it would only return a list of individual disciplines. This is why the bipartite network analysis works only with a research group where interdisciplinarity exists at the individual level.

The list of disciplines and the grain of disciplinary detail influence the results of the analysis. For example, a finer grain that distinguishes between community ecology, population ecology, and functional ecology would have resulted in different disciplinary communities. The distinction between these three ecology disciplines would be relevant in the case of a group specializing in ecology, but less relevant in our case study. It is therefore recommended to adjust the disciplinary grain to the diversity of the disciplines of the group studied.

\section{Interdisciplinary interactions}

Analysis of the interaction networks showed that scientific interactions (research and publication) in the group were stronger between researchers from the same disciplinary communities. Indeed, we observed that all disciplinary communities showed homophily for their publication interactions, which can be explained by the fact that mono-disciplinary papers may be easier to publish than interdisciplinary ones, as referees may lack the expertise needed to review manuscripts with multiple disciplinary backgrounds (Bruce et al. 2004). The three small disciplinary communities (computer sciences, economic and political sciences, and social sciences) showed homophily in the research interactions, which confirms that these small communities were isolated from other researchers in the group, as indicated by our initial analysis of researchers' disciplinary attachments. The interaction analysis showed that members of these communities tend to work among themselves, despite their small community size.

Disciplines influenced not only scientific interactions but also management interactions: disciplinary homophily was observed for the management interactions in three large disciplinary communities. This may be because members of the three large disciplinary communities are more often leaders of large projects and interact among themselves to manage projects ( $50 \%$ of the members of the large disciplinary communities had led a large project but only $9 \%$ of the members of the small disciplinary communities had done so).

Homophily is a clear driver of interactions, and it can take several forms beyond disciplinary homophily. After factoring out the effects of researchers' individual characteristics, our ERGMs confirmed that two researchers are more likely to interact if they are in the same disciplinary community, located at headquarters, or work in at least one region in common. For publication interactions, the strongest homophily is disciplinary, probably because publications tend to gather authors from the same disciplines. For management and research, the strongest homophily comes from working in the same world regions, as two people working in the same region are often involved in the same projects, share similar interests about their place-based research activities, and sometimes do fieldwork together.

In the studied group, place-based activities facilitate interactions or play the role of "boundary objects," a term coined by Star (1989) to describe "those objects that are plastic enough to be adaptable across multiple viewpoints" (p. 37). Boundary objects are often conceptual, but can also be concrete (Becker 2012). For example, "a forest can be a boundary object around which hikers, logging interests, conservationists, biologists, and owners organize their perspectives and seeks ways of coordinating them" (Wenger 1999, p. 107). The practice of fieldwork in the same places can foster discussions across disciplines about diverging or shared visions of the studied place and can lead to the redefining of research questions or approaches and build interdisciplinary research (Riaux and Massuel 2014). A powerful way to strengthen interdisciplinarity is by designing research projects that involve joint fieldwork by researchers of different disciplines (Marzano et al. 2006).

One limit of our analysis is that we chose to focus on the interactions inside the group and to exclude external interactions, because our analysis cannot be applied easily to the group of external 
collaborators, possibly very large. Some researchers can appear in our analysis with a low level of interdisciplinarity in their interactions within the group, while they may have a higher level of interdisciplinarity in their external interactions. Another limit is that we focus on the existence of management, research, and publication interactions between researchers rather than on their content. It would be interesting to complement the analysis with qualitative information on how the interactions contribute to interdisciplinarity: do interactions between two researchers from different disciplinary communities always lead to integrating different concepts and methods or contrasting and mutually enriching disciplinary perspectives? We could explore the degree of interaction, from simple notice-taking (i.e. one researcher notices the existence of other perspectives) to joint efforts (i.e. researchers share concepts from different disciplines and build on them) (Paxson 1996). We could also identify the outcomes of the interactions, such as new knowledge or new perspectives (Aram 2004). Another limit of our analysis is that we have not tried to explain professional interactions alongside personal relationships, such as friendship, despite the importance friendship between researchers may have for collaborative ties (Maldonado et al. 2009; Tse and Dasborough 2008).

\section{Interdisciplinary brokerage}

Some researchers occupy key positions in interaction networks, which gives them the power to create bridges between other researchers. When this brokerage role occurs across disciplinary communities, these brokers play the roles of "academic translators, conveyors of messages between representatives and audiences of different disciplines" (Molteberg et al. 2000, p.329) or are crossers of disciplinary borders in the sense given by Jollivet (1992). Our analysis shows that brokers in the studied group are not from a particular disciplinary community and do not only come from large communities. For example, a researcher from a small disciplinary community is a key broker within and across disciplines. This result can be explained by the size of the small disciplinary communities, which incentivizes building interactions with other communities. However, this is not the case for all members of small communities: some interact intensively as key interdisciplinary brokers while others do not. Thus, the brokerage roles are not explained by disciplines but rather by personal situations or motivations.

The broker analysis suggests that the research group functions in an 'integrative-synthesis' mode as defined by Barry et al. (2008). In this mode, the different disciplines in a group are at the same level, whereas in the 'subordination-service' mode, one discipline (or a few) dominates the others, and the others serve the dominant. In the subordination-service mode, we expect that the exchanges between researchers are channeled through researchers of the dominant discipline and, consequently, the brokers are predominantly from this discipline. The analysis of brokerage by discipline therefore makes it possible to reflect on the distribution of power in a research group. Brokers hold a centrality (also called 'betweenness centrality'), which is a form of power-that of transmitting information, facilitating collaborations, or blocking them (Di Gregorio et al. 2019; Ingold 2011). The integrative-synthesis mode, suggested by our analysis, reflects equity in the distribution of power between disciplines, while the subordination-service mode highlights power relationships between disciplines.

\section{Individual and collective interdisciplinarity}

In the studied group, researchers with high individual interdisciplinarity are less interdisciplinary in their interactions (without having fewer interactions in general). As we have expected that researchers with different disciplines interact more across disciplines, this result is surprising. One reason may be that we have not analyzed interactions outside the group: researchers with high individual interdisciplinarity may have interdisciplinary interactions with researchers from other groups, uncaptured in our study. Another reason for this result may be that researchers with a high individual interdisciplinarity feel less need to work with researchers from other disciplines. For 
example, a forest scientist supervising a thesis on the role of forests in water regulation may invite a hydrologist to co-supervise, whereas a researcher trained in both forest sciences and hydrology may not. Interdisciplinary collaboration may not be best developed by 'jacks of all trades' (Nash et al. 2003), i.e. researchers who have gained many disciplinary skills. As interdisciplinarity is sometimes defined as being an attribute of researchers who learn to understand each other without losing their own identities (Hunt 1994), interdisciplinarity may be better fostered by 'jacks of a few trades, master of one.'

Given the small size of the study in terms of the number of researchers investigated, the negative correlations between individual interdisciplinarity and the contribution to collective interdisciplinarity should not be generalized. Findings may differ in other research groups focusing on the same topics or other sustainability domains such as ocean ecosystems, soil sustainability, or climate change. The peculiarities of the studied group are shown for example by the effect of seniority (which does not influence the contribution of researchers to interdisciplinarity or decrease interactions in management). This result can seem counterintuitive, as we could expect that more established or senior researchers are more capable of connecting people from diverse disciplines and interact more with other group members. Indeed, in many research groups, senior researchers are central in management and have their names on most papers, but it is not the case of the studied group. This group does not have a hierarchical structure and is composed of researchers with diverse personal trajectories, having alternated between field action-research and more academic research, or between management, teaching and research. For example, some senior researchers of this group conduct an applied research with limited involvement in publications or management. The reward system in place in the group may explain that these trajectories are different from typical academic careers, because it assesses the performance of researchers not only on publications but also on consulting activities, fundraising, and policy or societal impacts, among others. Reward systems in academia have been identified as important barriers or incentives to interdisciplinarity (Bruce et al. 2004; Haider et al. 2018).

\section{Researcher characteristics}

The propensity of researchers to act as interdisciplinary brokers cannot be explained by their disciplines or individual interdisciplinarity but partially by their individual characteristics. Surprisingly, no characteristic explains the levels of individual interdisciplinarity (Fig. 6). For example, individual interdisciplinarity is not correlated to seniority: on the one hand, the youngest researchers might have received more interdisciplinary training but, on the other side, more senior researchers might have learned new disciplinary perspectives over the course of their careers.

Researcher characteristics are good descriptors of the role of researchers in interdisciplinary brokerage: leaders of large projects are interdisciplinary brokers for research interactions, recognized researchers for publication interactions, and management committee members for all types of interactions. As seniority has no effect on interdisciplinary brokerage, we can conclude that, in the studied research group, seniority is a bad descriptor of the role of researchers in interdisciplinarity. Because of the diversity of personal trajectories in the group, recognition, project leadership, and participation in management committee matter more than seniority.

Because both social and cognitive phenomena drive interdisciplinary research, individual capacities or motivations matter in explaining individual and collective interdisciplinarity (Wagner et al. 2011). Cognitive analyses of interdisciplinarity could be applied to explore how the mind of a single person can integrate different disciplinary perspectives or be confronted with different perspectives (Bromme 2000; Repko et al. 2007). Such analyses would be relevant for identifying strategies around improving how interdisciplinary groups function (O'Donnell and Derry 1997). 


\section{Conclusion}

Interdisciplinary research is needed to build knowledge in sustainability science. In this paper, we have explored how individual interdisciplinarity at the level of researchers interacts with collective interdisciplinarity in a research group on sustainability science. We applied social network analysis tools to the case of a group working in the field of forest sustainability science in order to test the hypothesis that researchers with high individual interdisciplinarity have more interdisciplinary interactions or play a role as interdisciplinary brokers. Our results rejected the hypothesis: researchers with high individual interdisciplinarity had fewer interdisciplinary interactions than others. They also showed that disciplines or interdisciplinarity did not explain brokerage roles, which were better explained by the personal characteristics of researchers. These findings, specific to the studied research group, call more research on the interactions between individual and collective interdisciplinarity. Further research is also needed to understand how social and cognitive factors drive interdisciplinary research. Our analysis also highlighted the role of place-based activities as boundary objects in facilitating interactions. The design of place-based research projects with researchers of different disciplines is a promising way of strengthening interdisciplinarity.

\section{Acknowledgements and disclosures}

This study was funded by the French funding agency for research (project TRASSE ANR-17-CE320012). The authors thank participants for their responses to the survey. The authors declare that they have no conflict of interest.

\section{References}

Aboelela SW, Larson E, Bakken S, Carrasquillo O, Formicola A, Glied SA, Haas J, Gebbie KM (2007a) Defining interdisciplinary research: Conclusions from a critical review of the literature. Health services research 42: 329346

Aboelela SW, Merrill JA, Carley KM, Larson E (2007b) Social network analysis to evaluate an interdisciplinary research center. Journal of Research Administration 38: 61-75

Aram JD (2004) Concepts of interdisciplinarity: Configurations of knowledge and action. Human Relations 57 : $379-412$

Barry A, Born G, Weszkalnys G (2008) Logics of interdisciplinarity. Economy and Society 37: 20-49

Becker E (2012) Social-ecological systems as epistemic objects. In: Glaser M (ed) Human-Nature Interactions in the Anthropocene, Routledge, pp 55-77

Bennett NJ, Roth R, Klain SC, Chan KM, Clark DA, Cullman G, Epstein G, Nelson MP, Stedman R, Teel TL (2017) Mainstreaming the social sciences in conservation. Conservation Biology 31: 56-66

Biancani S, McFarland DA (2013) Social networks research in higher education. Higher education: Handbook of theory and research, Springer, pp 151-215

Binz-Scharf MC, Kalish Y, Paik L (2015) Making science: New generations of collaborative knowledge production. American Behavioral Scientist 59: 531-547

Blanchard A, Vanderlinden J-P (2010) Dissipating the fuzziness around interdisciplinarity: the case of climate change research. SAPIENS Surveys and Perspectives Integrating Environment and Society

Boyack KW, Klavans R (2014) Creation of a highly detailed, dynamic, global model and map of science. Journal of the Association for Information Science and Technology 65: 670-685

Bromme R (2000) Beyond one's own perspective: The psychology of cognitive interdisciplinarity. In: Weingart $\mathrm{P}$, Stehr N (eds) Practicing interdisciplinarity, University of Toronto Press, Toronto, pp 115-133

Bruce A, Lyall C, Tait J, Williams R (2004) Interdisciplinary integration in Europe: the case of the Fifth Framework programme. Futures 36: 457-470 
Butts CT (2016) sna: Tools for Social Network Analysis. R package version 2.4. https://CRAN.Rproject.org/package=sna.

Butts CT, Morris M, Krivitsky PN, Almquist Z, Handcock MS, Hunter DR, Goodreau SM, de-Moll SB (2015) Introduction to Exponential-family Random Graph (ERG or $\mathrm{p}^{*}$ ) modeling with ergm. CRAN project, http://cran.r-project.org/web/packages/ergm/vignettes/ergm.pdf,

Calvert J (2010) Systems biology, interdisciplinarity and disciplinary identity. In: Parker J, Vermeulen N, Penders $B$ (eds) Collaboration in the new life sciences, Ashgate Publishing, pp 201-218

Cranmer SJ, Desmarais BA (2011) Inferential network analysis with exponential random graph models. Political Analysis 19: 66-86

Csardi G (2018) igraph: Routines for simple graphs and network analysis, version 1.2.2. https://cran.rproject.org/package=igraph,

Cummings JN, Kiesler S (2005) Collaborative research across disciplinary and organizational boundaries. Social studies of science 35: 703-722

Davis M (1992) Disciplines, interdisciplinarity and migration in family research. Research Evaluation 2: 177-187

Di Gregorio M, Fatorelli L, Paavola J, Locatelli B, Pramova E, Nurrochmat DR, May PH, Brockhaus M, Sari IM, Kusumadewi SD (2019) Multi-level governance and power in climate change policy networks. Global Environmental Change 54: 64-77

Fraser ED, Dougill AJ, Hubacek K, Quinn CH, Sendzimir J, Termansen M (2011) Assessing vulnerability to climate change in dryland livelihood systems: conceptual challenges and interdisciplinary solutions. Ecology and Society 16

Gould RV, Fernandez RM (1989) Structures of mediation: A formal approach to brokerage in transaction networks. Sociological methodology: 89-126

Hackenburg DM, Adams A, Brownson K, Borokini IT, Gladkikh TM, Herd-Hoare SC, Jolly H, Kadykalo AN, Kraus EB, McDonough KR (2019) Meaningfully engaging the next generation of ecosystem services specialists. Ecosystem Services 40: 101041

Haider L, Hentati-Sundberg J, Giusti M, Goodness J, Hamann M, Masterson VA, Meacham M, Merrie A, Ospina D, Schill C, Sinare H (2018) The undisciplinary journey: early-career perspectives in sustainability science. Sustainability Science 13: 191-204

Handcock MS, Hunter DR, Butts CT, Goodreau SM, Krivitsky PN, Bender-deMoll S, Morris M (2016) Package 'statnet': Software Tools for the Statistical Analysis of Network Data, version 2016.9. https://cran.rproject.org/package=statnet,

Hein CJ, Ten Hoeve JE, Gopalakrishnan S, Livneh B, Adams HD, Marino EK, Susan Weiler C (2018) Overcoming early career barriers to interdisciplinary climate change research. Wiley Interdisciplinary Reviews: Climate Change 9: e530

Hunt L (1994) The virtues of disciplinarity. Eighteenth-Century Studies 28: 1-7

Huutoniemi K, Klein JT, Bruun H, Hukkinen J (2010) Analyzing interdisciplinarity: Typology and indicators. Research Policy 39: 79-88

Ingold K (2011) Network structures within policy processes: Coalitions, power, and brokerage in Swiss climate policy. Policy studies journal 39: 435-459

Jollivet M (ed) (1992) Sciences de la nature, sciences de la société: Les passeurs de frontières. CNRS editions, Paris, $589 \mathrm{pp}$

Jung Y, Kim E, Kim W (2019) The scientific and technological interdisciplinary research of government research institutes: network analysis of the innovation cluster in South Korea. Policy Studies: 1-20

Kates RW (2011) What kind of a science is sustainability science? Proceedings of the National Academy of Sciences 108: 19449 
Kibanov M, Heiberger RH, Rödder S, Atzmueller M, Stumme G (2019) Social studies of scholarly life with sensor-based ethnographic observations. Scientometrics 119: 1387-1428

Knoke D, Yang S (2008) Social network analysis. Sage, Thousand Oaks, CA

Komiyama H, Takeuchi K (2006) Sustainability science: building a new discipline. Sustainability science 1: 1-6

Krackhardt D, Stern RN (1988) Informal networks and organizational crises: An experimental simulation. Social psychology quarterly: 123-140

Leydesdorff L, Rafols I (2009) A global map of science based on the ISI subject categories. Journal of the American Society for Information Science and Technology 60: 348-362

Locatelli B, Pramova E, Di Gregorio M, Brockhaus M, Armas Chávez D, Tubbeh R, Sotés J, Perla J (2020) Climate change policy networks: Connecting adaptation and mitigation in multiplex networks. Climate Policy 20: 354372

Long JC, Cunningham FC, Braithwaite J (2013) Bridges, brokers and boundary spanners in collaborative networks: a systematic review. BMC health services research 13: 158

Lusher D, Robins G (2013) Formation of Social Network Structure. In: Lusher D, Robins G, Koskinen J (eds) Exponential Random Graph Models for Social Networks: Theory, Methods, and Applications, Cambridge University Press, Cambridge, pp 16-28

Maldonado H, Klemmer SR, Pea RD (2009) When is collaborating with friends a good idea? insights from design education. Proceedings of the 9 th international conference on Computer supported collaborative learningVolume 1, pp 227-231

Marzano M, Carss DN, Bell S (2006) Working to make interdisciplinarity work: Investing in communication and interpersonal relationships. J Agric Econ 57: 185-197

McPherson M, Smith-Lovin L, Cook JM (2001) Birds of a feather: Homophily in social networks. Annual review of sociology 27: 415-444

Molteberg E, Bergstrøm C, Haug R (2000) Interdisciplinarity in development studies: Myths and realities. Forum for Development Studies. Taylor \& Francis, pp 317-330

Nash JM, Collins BN, Loughlin SE, Solbrig M, Harvey R, Krishnan-Sarin S, Unger J, Miner C, Rukstalis M, Shenassa E (2003) Training the transdisciplinary scientist: a general framework applied to tobacco use behavior. Nicotine \& Tobacco Research 5: S41-S53

Neal JW, Neal ZP, Mills KJ, Lawlor JA, McAlindon K (2019) What types of brokerage bridge the researchpractice gap? The case of public school educators. Social Networks 59: 41-49

O’Donnell AM, Derry SJ (1997) Cognitive processes in interdisciplinary groups: Problems and possibilities. In: Derry SJ, Schunn CD, Gernsbacher MA (eds) Interdisciplinary Collaboration: An Emerging Cognitive Science, Lawrence Erlbaum Publishers, Mahwah, NJ, pp 51-82

Paxson TD (1996) Modes of interaction between disciplines. The Journal of General Education 45: 79-94

Porter A, Rafols I (2009) Is science becoming more interdisciplinary? Measuring and mapping six research fields over time. Scientometrics 81: 719-745

Qin J, Lancaster FW, Allen B (1997) Types and levels of collaboration in interdisciplinary research in the sciences. Journal of the American Society for information Science 48: 893-916

R Core Team (2018) R: A language and environment for statistical computing. R version 3.5 .1 (2018-07-02). R Foundation for Statistical Computing, Vienna, Austria, https://www.r-project.org/,

Rafols I, Meyer M (2010) Diversity and network coherence as indicators of interdisciplinarity: case studies in bionanoscience. Scientometrics 82: 263-287

Repko A, Navakas F, Fiscella J (2007) Integrating interdisciplinarity: How the theories of common ground and cognitive interdisciplinarity are informing the debate on interdisciplinary integration. Issues in Interdisciplinary Studies 25: 1-31 
Riaux J, Massuel S (2014) Building a Sociohydrological Perspective (2). Sharing Fieldwork to Develop Scientific Convergences. Natures Sciences Sociétés 22: 329-339

Robins G, Lusher D (2013a) Illustrations: Simulation, Estimation, and Goodness of Fit. In: Lusher D, Robins G, Koskinen J (eds) Exponential Random Graph Models for Social Networks: Theory, Methods, and Applications, Cambridge University Press, Cambridge, pp 167-186

Robins G, Lusher D (2013b) What Are Exponential Random Graph Models? In: Lusher D, Robins G, Koskinen J (eds) Exponential Random Graph Models for Social Networks: Theory, Methods, and Applications, Cambridge University Press, Cambridge, pp 9-15

Schoolman ED, Guest JS, Bush KF, Bell AR (2012) How interdisciplinary is sustainability research? Analyzing the structure of an emerging scientific field. Sustainability Science 7: 67-80

Schummer J (2004) Multidisciplinarity, interdisciplinarity, and patterns of research collaboration in nanoscience and nanotechnology. Scientometrics 59: 425-465

Star SL (1989) The structure of ill-structured solutions: Boundary objects and heterogeneous distributed problem solving. In: Gasser L, Huhns MN (eds) Distributed artificial intelligence, Morgan Kaufmann Publishers, San Mateo, California, pp 37-54

Tse HH, Dasborough MT (2008) A study of exchange and emotions in team member relationships. Group \& Organization Management 33: 194-215

Uddin S, Hossain L, Rasmussen K (2013) Network effects on scientific collaborations. PloS one 8: e57546

van Leeuwen T, Tijssen R (2000) Interdisciplinary dynamics of modern science: analysis of cross-disciplinary citation flows. Research Evaluation 9: 183-187

Van Noorden R (2015) Interdisciplinary research by the numbers. Nature 525: 306-307

Van Rijnsoever FJ, Hessels LK (2011) Factors associated with disciplinary and interdisciplinary research collaboration. Research policy 40: 463-472

Vojak BA, Price RL, Griffin A (2010) Corporate innovation. In: Frodeman R (ed) The Oxford Handbook of Interdisciplinarity, Oxford University Press, Oxford, UK, pp 546-559

Wagner CS, Roessner JD, Bobb K, Klein JT, Boyack KW, Keyton J, Rafols I, Börner K (2011) Approaches to understanding and measuring interdisciplinary scientific research (IDR): A review of the literature. Journal of informetrics 5: 14-26

Wang J, Thijs B, Glänzel W (2015) Interdisciplinarity and impact: Distinct effects of variety, balance, and disparity. PloS one 10

Wenger E (1999) Communities of practice: Learning, meaning, and identity. Cambridge university press

Yang C, Park H, Heo J (2010) A network analysis of interdisciplinary research relationships: The Korean government's R\&D grant program. Scientometrics 83: 77-92 


\section{Supplementary materials for the paper "Collective and individual interdisciplinarity in a sustainability research group: A social network analysis"}

\section{SM1. Basic network descriptors}

The three interaction networks (Management, Research and Publication) differ in terms of density and transitivity (Table SI1). Researchers in the group have fewer interactions for publications than for research or management. The publication network is also less transitive: the group has fewer small clusters (triads interacting with each other) for publication than for research or management. The network of interaction of any form is dense: two researchers taken at random from the group have about two chances in three to have an interaction of any form (density 0.65 in the "all interactions" network).

Table SM1. Density and transitivity of the interaction networks. Density is the total number of ties in the network divided by the maximum possible number. Transitivity (or clustering) is the degree to which nodes in a graph tend to cluster together (i.e. the degree to which $A$ and $B$ are tied if $A$ and $B$ are tied to a third actor)

\begin{tabular}{lll}
\hline & Density & Transitivity \\
\hline Management interactions & 0.52 & 0.63 \\
\hline Research interactions & 0.51 & 0.61 \\
\hline Publication interactions & 0.31 & 0.41 \\
\hline All interactions & 0.65 & 0.73 \\
\hline
\end{tabular}

\section{SM2. ERGM diagnostics and goodness-of-fit}

We used the mcmc.diagnostics tool in the ergm package in R (Handcock et al., 2017) to check visually that the sample statistics varied randomly during the Markov Chain Monte Carlo simulation around the values of this statistic in the observed network (Fig. SM1 to SM3, left). We also checked that the difference between the observed and simulated values of the sample statistics has a bellshaped distribution centered at 0 (Fig. SM1 to SM3, right) (Butts et al., 2015).

We also examined the goodness of fit of the model by checking whether networks simulated by the model reproduced some global properties of the observed network, for example the distribution of in-degrees or edgewise shared partners. The diagnostics showed that the model provided a good representation of the observed network (Fig. SM4), as almost all the observations (dark black line) fell within the $95 \%$ confidence interval of the simulations (gray lines). 


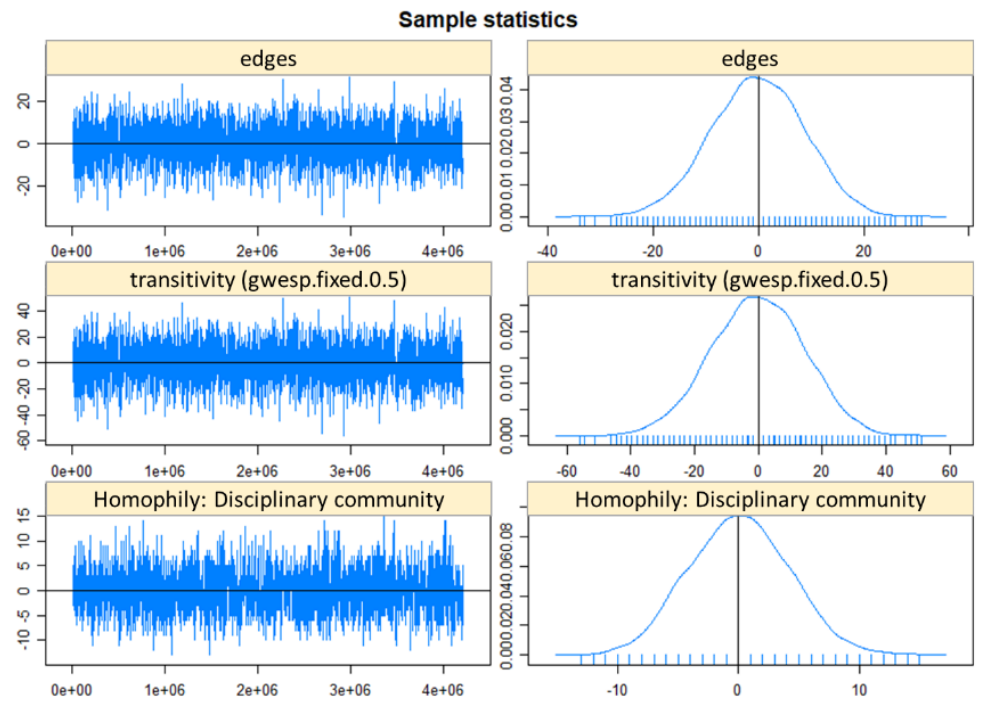

Figure SM1. Simple diagnostic plots for a few MCMC sampled statistics produced from fitting an ERGM model for the network with all forms of interactions.

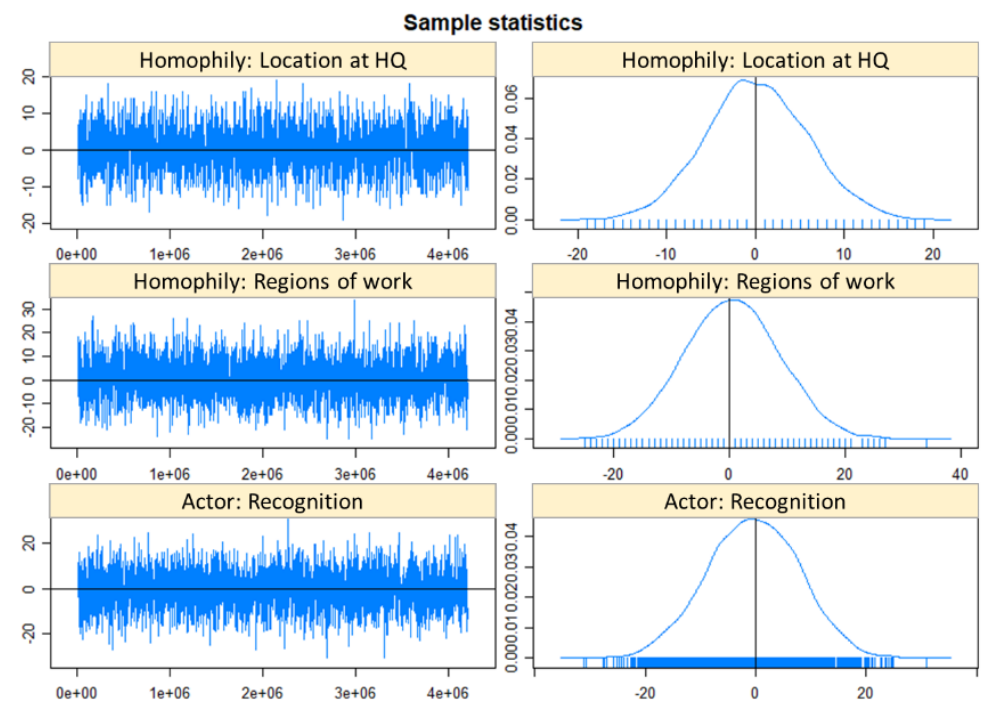

Figure SM2. Simple diagnostic plots for a few MCMC sampled statistics produced from fitting an ERGM model for the network with all forms of interactions. 


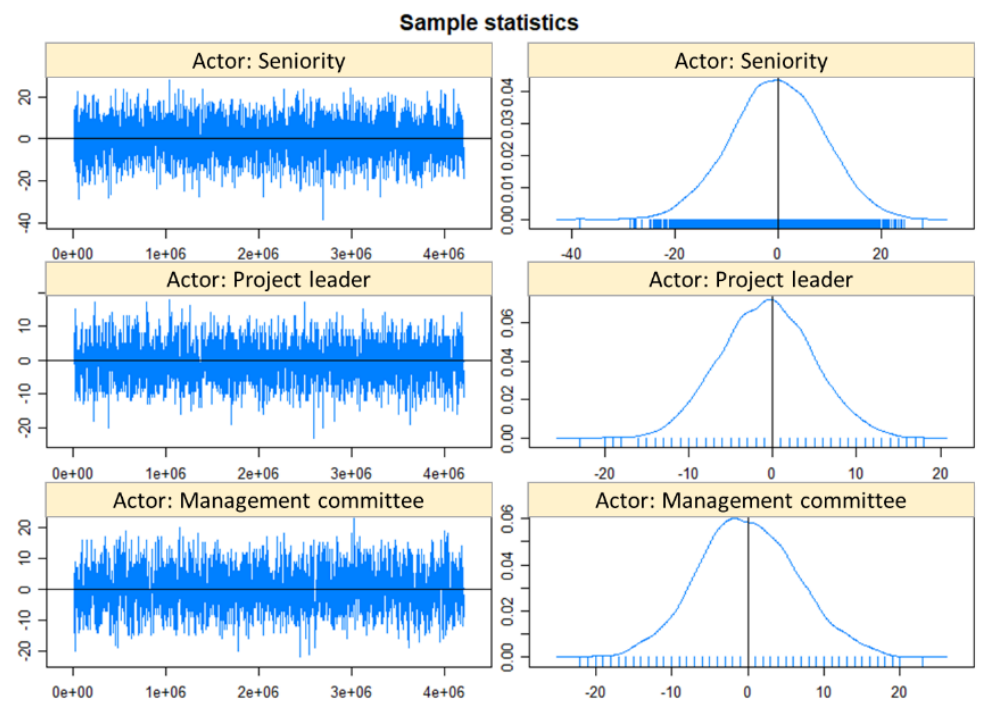

Figure SM3. Simple diagnostic plots for a few MCMC sampled statistics produced from fitting an ERGM model for the network with all types of interactions.
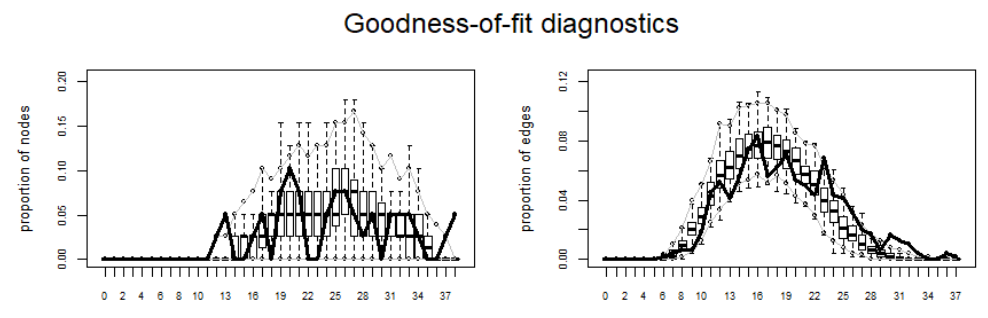

degree

edge-wise shared partners
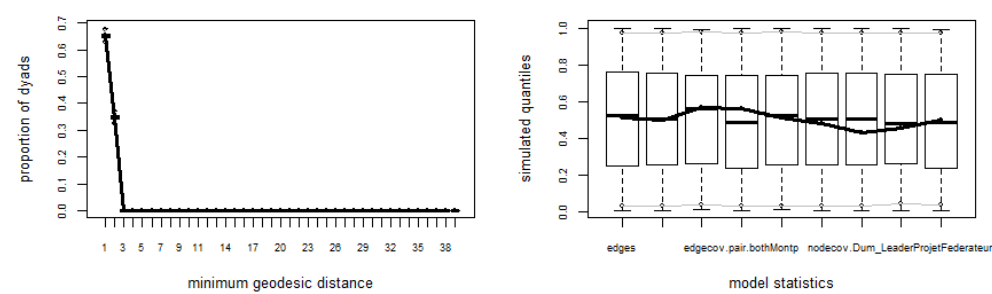

Figure SM4. Goodness-of-fit diagnostics for the network with all types of interactions 